\title{
Spatial attention does improve temporal discrimination
}

\author{
Ana B. Chica \\ University of Granada, Granada, Spain \\ and Dalhousie University, Halifax, Nova Scotia, Canada \\ AND \\ JoHn Christie \\ Dalhousie University, Halifax, Nova Scotia, Canada
}

\begin{abstract}
It has recently been stated that exogenous attention impairs temporal-resolution tasks (Hein, Rolke, \& Ulrich, 2006; Rolke, Dinkelbach, Hein, \& Ulrich, 2008; Yeshurun, 2004; Yeshurun \& Levy, 2003). In comparisons of performance on spatially cued trials versus neutral cued trials, the results have suggested that spatial attention decreases temporal resolution. However, when performance on cued and uncued trials has been compared in order to equate for cue salience, typically speed-accuracy trade-offs (SATs) have been observed, making the interpretation of the results difficult. In the present experiments, we aimed at studying the effect of spatial attention in temporal resolution while using a procedure to control for SATs. We controlled reaction times (RTs) by constraining the time to respond, so that response decisions would be made within comparable time windows. The results revealed that when RT was controlled, performance was impaired for cued trials as compared with neutral trials, replicating previous findings. However, when cued and uncued trials were compared, performance was actually improved for cued trials as compared with uncued trials. These results suggest that SAT effects may have played an important role in the previous studies, because when they were controlled and measured, the results reversed, revealing that exogenous attention does improve performance on temporal-resolution tasks.
\end{abstract}

Attention may be conceived of as a mechanism that helps us select relevant information for behavior. Spatial attention can be oriented to locations in space voluntarily (endogenously) or involuntarily (exogenously). These two forms of orienting have been proven to constitute two independent attentional systems that produce different effects on behavior (see Klein, 2004, for a recent review). Attending to a location in space has been found to improve visual-spatial tasks, such as those used to study contrast sensitivity (Cameron, Tai, \& Carrasco, 2002), spatial resolution (Yeshurun \& Carrasco, 1998), and acuity (Baldassi $\&$ Burr, 2000). However, a relatively recent and surprising finding suggests that spatial attention is not beneficial for all tasks. In particular, increasing spatial attention seems to degrade performance on visual temporal-resolution tasks (Hein, Rolke, \& Ulrich, 2006; Rolke, Dinkelbach, Hein, \& Ulrich, 2008; Yeshurun \& Levy, 2003). Temporal resolution here refers to the ability to detect rapid changes in light intensity over time or to resolve temporal details (Levine, 2000). It has been postulated that attention impairs the ability to detect stimuli that are presented in a rapid succession. For example, if we are driving our car and paying attention to the cars on our right as we prepare to change lanes, the orienting of attention to that location impairs our ability to discriminate when the next car on the right will arrive.

Yeshurun and Levy (2003) have explained the dissociation of the effects of spatial attention in spatial- and temporal-resolution tasks with a physiological theory about the activity of the magnocellular and parvocellular systems. They postulate that spatial attention facilitates the activity of parvocellular neurons at the attended location, which, at the same time, inhibits the activity of magnocellular neurons. Parvocellular neurons have smaller receptive fields than do magnocellular neurons, which could account for the increase in spatial resolution if these neurons were activated preferentially. Nevertheless, parvocellular neurons have longer response durations than do magnocellular neurons (see, e.g., Merigan \& Maunsell, 1993). This prolonged reaction time (RT) may produce a decrement in performance when stimulation detection is separated by a brief interval, therefore reducing temporal resolution. In summary, Yeshurun and Levy proposed that attention facilitates the activity of parvocellular neurons, which increases spatial resolution, but at the same time decreases temporal resolution.

Yeshurun and Levy (2003, Experiment 1) provided the first demonstration of decreased temporal resolution at an

A. B.Chica, anachica@ugr.es 
attended location. In their task, participants were asked to judge whether one or two disks were presented (both at the same spatial location). That is, the task was to detect a temporal gap within the stimulus. This target was preceded by either a spatially informative cue or a neutral cue. The spatial cue consisted of a small green line situated above the disk: This cue was always presented at the same location as that of the target (i.e., $100 \%$ valid cue). The authors postulated that the spatial cue captured attention in a "stimulusdriven, automatic manner" (p. 226; what we have referred to as exogenous attention). However, because the cue was $100 \%$ predictive about the target location, it is not possible to disentangle the contribution of endogenous and exogenous attention to the effect observed (Chica, Lupiáñez, \& Bartolomeo, 2006). ${ }^{1}$ Yeshurun and Levy compared performance on spatially cued trials with that on neutral cue trials. The neutral cue consisted of two green lines (each 17 times larger than the spatially informative cue) presented above and below the entire display. Their results clearly showed that perceptual sensitivity (as measured by $d^{\prime}$ ) was impaired for spatially cued trials as compared with neutral cue trials. Response bias effects were also observed. Participants adopted a more conservative criterion (reluctance to respond that a gap was present) in spatially cued trials than in neutral cue trials.

Yeshurun (2004) noticed that their results could be explained alternatively as resulting from local interference. The neural activity of the spatial cue could be integrated with that of the target, leading to a worse performance on spatially cued trials. Yeshurun (2004, Experiment 1) replicated her previous finding by using the same spatial cue and a different neutral cue. Each neutral cue (above and below the display) was composed of nine horizontal bars (each one identical to the spatial cue). Again, spatially cued trials showed a decreased perceptual sensitivity and a more conservative criterion than did neutral cue trials. Therefore, when one compares the performance on spatially cued trials with that on the neutral trials in Yeshurun's investigations, it seems that attention impaired temporal resolution.

Note, however, that the neutral cues used in the experiments described above were bigger and much more salient than the spatial cue. In 1984, when the cost and benefit paradigm started to be used regularly, Jonides and Mack (1984) noted that, in order to compare performance for spatial cues and neutral cues, both cues had to be matched in physical appearance, potential alerting, and ease of encoding. It can be noticed easily that, in the experiments just described, the neutral cues were not matched in size and salience with the spatial cue. It could be the case that more salient cues produce larger alerting effects, which could affect performance in temporal-resolution tasks (i.e., being more alerted could improve temporal resolution on neutral cue trials as compared with spatially cued trials). Moreover, the fact that the cues were different could have led to different preparatory states in the participant. In Yeshurun and Levy's (2003) study, the spatial cue directed attention to a small portion of the visual field, where participants were $100 \%$ sure that the target would be presented. However, when the cue was neutral, atten- tion was widely distributed through the entire visual field, and there was no certainty as to where the target would be presented. Jonides and Mack correctly asserted that the best way to test the cuing effect is to use a cue that can appear at either the same location as can the target (cued trials) or at the opposite location (uncued trials). This manipulation seems especially appropriate because, from the participant's point of view, it is not possible to know whether the trial will be cued or uncued until the target appears. Therefore, the comparison of cued and uncued trials would equate all of the cognitive processes (and preparatory states) related with the processing of the cue until the target is presented.

In this vein, Rolke et al. (2008, Experiment 1) first replicated Yeshurun and Levy's (2003) experiment, finding that $d^{\prime}$ was larger for neutral cue trials than for spatially cued trials, and response criterion was more conservative for spatially cued trials than for neutral cue trials. In that experiment, RT was also faster for neutral trials. Rolke et al. (2008) noted that the difference in luminance and size between the cues might explain the better performance in neutral cue trials. The neutral cue might be more alerting than the spatial cue. To deal with this issue, Rolke et al. (2008, Experiment 2) used a same spatial cue that could appear at either the same location as that of the target (cued trials, $75 \%$ of the trials) or at the opposite location (uncued trials, $25 \%$ of the trials). Again, they found that $d^{\prime}$ was impaired on cued trials as compared with uncued trials, and a more conservative criterion was adopted for responding on cued trials. However, a speedaccuracy trade-off (SAT) was also present, with RT being faster for cued than for uncued trials (this RT effect was much larger in size than the accuracy effect). In summary, accuracy was impaired for cued versus uncued trials, although responses were faster, and a more conservative criterion was used in responding on cued than on uncued trials. Conscious of the problem of finding an SAT effect, the authors ran a third experiment in which they asked participants to withhold their response until an imperative signal was presented after $1 \mathrm{sec}$. Under these conditions, $d^{\prime}$ was again lower for cued versus uncued trials, although no evidence of SAT was found. As in the previous experiments, participants also adopted a more conservative criterion to respond to cued trials (see the Discussion section for an extended comment on this experiment).

Hein et al. (2006, Experiment 1) extended the previous findings to a temporal order judgment (TOJ) task. Such tasks are believed to measure the arrival times of the stimulation to the perceptual system. In particular, if attention impairs temporal resolution, focusing attention to a location in space should slow the arrival of this information. In Hein et al.'s study, the typical cue-benefit paradigm was used (see Posner \& Cohen, 1984), in which a fixation point and two markers are presented and a peripheral cue precedes the target. The peripheral cue consisted of the brightening of one of the markers and was not predictive of where the subsequent targets would appear. As in Rolke et al.'s (2008) Experiment 2, performance on cued trials was compared with that on uncued trials. In Hein et al.'s TOJ task, the target consisted of two dots, successively presented at different 
spatial locations, within either the left or the right marker. The participant's task was to judge which dot came first. The results were consistent with those of the previous experiments, showing that TOJs were impaired for cued trials versus uncued trials and indicating that attention impaired temporal resolution. However, once again, an SAT was found, with RTs being faster for cued trials than for uncued trials (see Table 1 for a summary of the evidence about attention and temporal-resolution tasks to date).

In summary, the empirical evidence in the study conducted by Yeshurun and Levy (2003) did not provide sufficient support for the conclusion that exogenous attentional orienting impairs temporal resolution (1) because the neutral cue was not matched in size and salience with the spatial cue, and (2) the use of different cues produced different expectations and preparatory states in the participant, thus leading to different cuing effects that might not have been produced by the orienting of attention itself but rather by different alerting effects (Jonides \& Mack, 1984). Moreover, when performance on cued trials has been compared with that on uncued trials (Hein et al., 2006; Rolke et al., 2008), SAT effects have also been found, with responses faster but less accurate on cued trials and yielding a result that is essentially uninterpretable. In an effort to follow up this research, in two preliminary studies, we used methods very similar to Rolke et al.'s (2008). In both studies, cued RT was faster than uncued, but there was also a trend toward an SAT, with uncued performance being more accurate than cued performance. Because this was again a potentially inconclusive SAT finding, and because of the impossibility of drawing strong conclusions from such data, the present studies were conducted.

The aim of the present experiments was to study the effect of spatial attention in temporal resolution while controlling for any possible SATs. We constrained RTs in different blocks, from very quick responses after the target was presented to relatively more slow responses (see the Method section for details of the specific timing). This al- lows us to estimate the effect of attention on temporal processing at different speeds, when the available information for responding is accumulating. RT was constrained by the deadline method, in which participants were asked to respond within a specified time window. The deadline was manipulated between blocks of trials in order to produce speed-accuracy shifts (see, e.g., Ivanoff \& Klein, 2006; McCormick \& Francis, 2005). In the first experiment, we replicated Yeshurun and Levy (2003), comparing performance on spatially cued trials versus that on neutral cue trials. In the second experiment, we used the same cue, which could appear randomly at either the target location (cued trials) or at the opposite location (uncued trials, as in Hein et al., 2006, and Rolke et al., 2008). The results showed that, when speed stress was controlled, perceptual sensitivity was still impaired on spatially cued trials as compared with neutral cue trials. However, perceptual sensitivity was in fact enhanced on cued trials versus uncued trials, revealing that exogenous spatial attention improves temporal resolution.

\section{EXPERIMENT 1 Spatially Cued Versus Neutral Trials}

This experiment was a replication of Yeshurun and Levy's (2003) Experiment 1, in which performance was compared on spatially cued trials and neutral cue trials. The spatial cue was $100 \%$ predictive of where the target would appear, and stimuli were designed to closely match those described by Yeshurun and Levy. In order to control for SAT effects, a tone signaled (at four different levels) when to respond.

\section{Method}

Participants. Twelve naive participants ( 3 males and 9 females, mean age of 21 years) from Dalhousie University took part in the experiment for course credits. All of the participants who took part in Experiments 1 and 2 reported having normal or corrected-to-normal vision and normal hearing. The experiments were conducted in accordance with the ethical guidelines laid down by the Tri-council

Table 1

Summary of the Existing Evidence (Including the Present Study) About the Effect of Attention in Temporal-Resolution Tasks

\begin{tabular}{|c|c|c|c|c|c|c|c|}
\hline Study & Experiment & $\begin{array}{l}\text { Cue } \\
\text { Type }\end{array}$ & $\begin{array}{c}\% \\
\text { Trials }\end{array}$ & $\begin{array}{l}\text { Effect } \\
\text { on RT }\end{array}$ & $\begin{array}{l}\text { Effect } \\
\text { on } d^{\prime}\end{array}$ & $\begin{array}{l}\text { Effect on } \\
\text { Criterion }\end{array}$ & $\%$ Correct \\
\hline \multirow[t]{2}{*}{ Yeshurun \& Levy (2003) } & E1 & $\begin{array}{l}\text { Neutral } \\
\text { Spatial }\end{array}$ & $\begin{array}{r}50 \\
100\end{array}$ & $\begin{array}{l}\text { No } \\
\text { differences }\end{array}$ & $\begin{array}{l}\text { Decreased } \\
\text { for cued }\end{array}$ & $\begin{array}{l}\text { More conservative } \\
\text { for cued }\end{array}$ & - \\
\hline & E1 & $\begin{array}{l}\text { Neutral } \\
\text { Spatial }\end{array}$ & $\begin{array}{r}50 \\
100\end{array}$ & $\begin{array}{l}\text { Faster for } \\
\text { neutral }\end{array}$ & $\begin{array}{l}\text { Decreased } \\
\text { for cued }\end{array}$ & $\begin{array}{l}\text { More conservative } \\
\text { for cued }\end{array}$ & - \\
\hline \multirow[t]{2}{*}{ Rolke et al. (2008) } & E2 & $\begin{array}{l}\text { Cued } \\
\text { Uncued }\end{array}$ & 75 & $\begin{array}{l}\text { Faster for } \\
\text { cued }\end{array}$ & $\begin{array}{l}\text { Decreased } \\
\text { for cued }\end{array}$ & $\begin{array}{l}\text { More conservative } \\
\text { for cued }\end{array}$ & - \\
\hline & E3* & $\begin{array}{l}\text { Cued } \\
\text { Uncued }\end{array}$ & 75 & $\begin{array}{l}\text { No } \\
\text { differences }\end{array}$ & $\begin{array}{l}\text { Decreased } \\
\text { for cued }\end{array}$ & $\begin{array}{l}\text { More conservative } \\
\text { for cued }\end{array}$ & - \\
\hline Hein et al. (2006) & E1 & $\begin{array}{l}\text { Cued } \\
\text { Uncued }\end{array}$ & 50 & $\begin{array}{l}\text { Faster for } \\
\text { cued }\end{array}$ & - & - & $\begin{array}{l}\text { Impaired TOJs } \\
\text { for cued }\end{array}$ \\
\hline \multirow[t]{2}{*}{ Present study } & E1 & $\begin{array}{l}\text { Neutral } \\
\text { Spatial }\end{array}$ & $\begin{array}{r}50 \\
100\end{array}$ & $\begin{array}{l}\text { No } \\
\text { differences }\end{array}$ & $\begin{array}{l}\text { Decreased } \\
\text { for cued }\end{array}$ & No differences & 一 \\
\hline & E2 & $\begin{array}{l}\text { Cued } \\
\text { Uncued }\end{array}$ & 50 & $\begin{array}{l}\text { No } \\
\text { differences }\end{array}$ & $\begin{array}{l}\text { Increased } \\
\text { for cued }\end{array}$ & No differences & - \\
\hline
\end{tabular}

Note— $\%$ Trials is the percentage of trials on which the cue correctly predicted the target's location ${ }^{*}$ This study tried to control for SAT effects by asking participants to withhold their response until $1 \mathrm{sec}$ after the target's offset. 
Policy on Human Ethics and overseen by the Department of Psychology, Dalhousie University.

Apparatus and Stimuli. A PC running E-Prime software (Schneider, Eschman, \& Zuccolotto, 2002) controlled the presentation of stimuli, timing operations, and data collection. The stimuli used in the experiment were presented against a black background. Participants were seated approximately $45 \mathrm{~cm}$ from the monitor. The fixation point consisted of a gray $1^{\circ} \times 1^{\circ}$ plus sign. The target consisted of a white circle, $2^{\circ}$ in diameter, presented at $5.8^{\circ}$ to the left or right of fixation. The spatial cue consisted of a green horizontal line subtending $1.5^{\circ} \times 0.4^{\circ}$, and situated $0.6^{\circ}$ above the target. The neutral cue consisted of two $25.5^{\circ} \times 0.4^{\circ}$ horizontal lines presented centrally above and below fixation.

Procedure. The sequence of events in a given trial is represented in Figure 1. Each trial started with a fixation cross that remained on the screen for the whole trial. After $1,000 \mathrm{msec}$, either the spatial or the neutral cue was presented randomly. The target was displayed at either the left or the right location $96 \mathrm{msec}$ later. In the neutral cue condition, the target appeared with equal probability at either the left or the right location. In the spatial-cue condition, the target was always presented at the same location as was the cue (as in the study of Yeshurun \& Levy, 2003, the cue was $100 \%$ predictive). In the no-gap condition, the target consisted of a white disk that appeared for $118 \mathrm{msec}$. In the gap condition, the white disk appeared for $47 \mathrm{msec}$, disappeared for $24 \mathrm{msec}$, and then appeared again for $47 \mathrm{msec}$ (total, $118 \mathrm{msec}$ ). After a variable interval (stimulus-tone interval, STI), a 94-msec tone was presented that opened a further 212-msec window in which to respond. Participants detected the ap- pearance of the gap, pressing the "yes" or "no" key (the " $\mathrm{z}$ " and "m" keys, counterbalanced between participants). The STI (defined as the time between the appearance of the gap, or the same moment in the no-gap condition, and the appearance of the tone) had four levels manipulated between blocks: 191, 263, 335, and $407 \mathrm{msec}$. Half of the participants experienced the four blocks in an ascending order, and the other half experienced the blocks in a descending order. Participants were encouraged to respond in every trial. If a response was not detected within time, the words NO RESPONSE were presented in red for $482 \mathrm{msec}$. Anticipatory responses were also indicated by the words TOO SOON for $482 \mathrm{msec}$. No feedback for correct or incorrect responses was provided in the experimental trials. The interstimulus interval, in which the fixation point was removed and the screen remained black, was $482 \mathrm{msec}$ in duration.

Each of the four blocks consisted of 200 trials, preceded by 24 practice trials. Practice trials were similar to the experimental trials, except that no tone for response was presented, participants could respond for 2,470 msec after target disappearance, and incorrect response feedback was provided. Each block consisted of a total of 50 trials for each experimental condition of cuing (cued vs. neutral trials) and gap condition (gap and no-gap trials). The task lasted for approximately $50 \mathrm{~min}$, and participants were allowed to rest after every 50 trials.

\section{Results}

Misses (11.1\% of trials), late responses (responses $482 \mathrm{msec}$ after the response was required; $0.34 \%$ of the trials), and early responses ( $4.8 \%$ of the trials) were re-

A

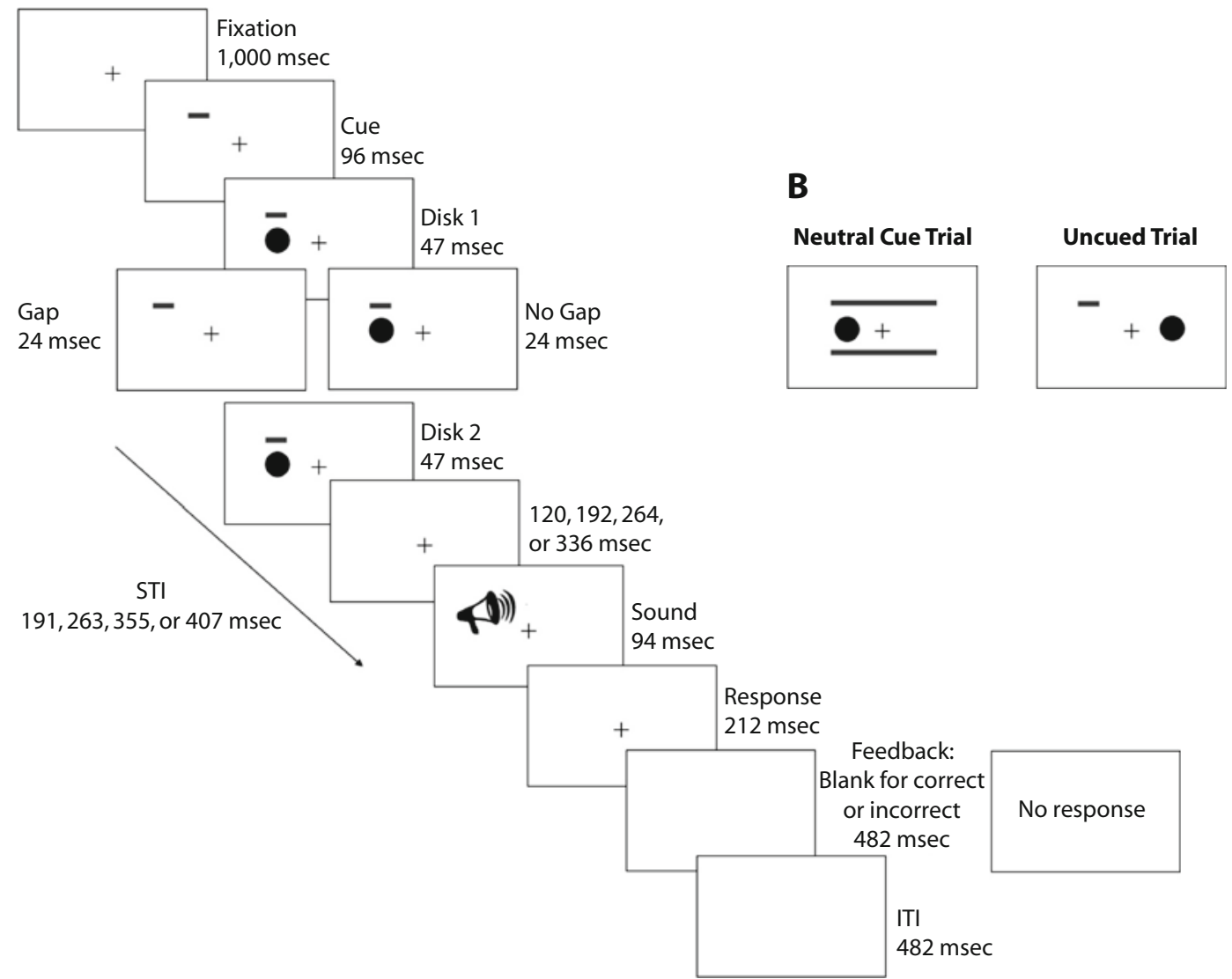

Figure 1. Sequence of events in a given trial. (A) A spatially cued trial is represented. (B) Representation of neutral cued targets and uncued targets. In Experiment 1, spatially cued trials were compared with neutral cue trials. In Experiment 2, cued and uncued trials were compared. 


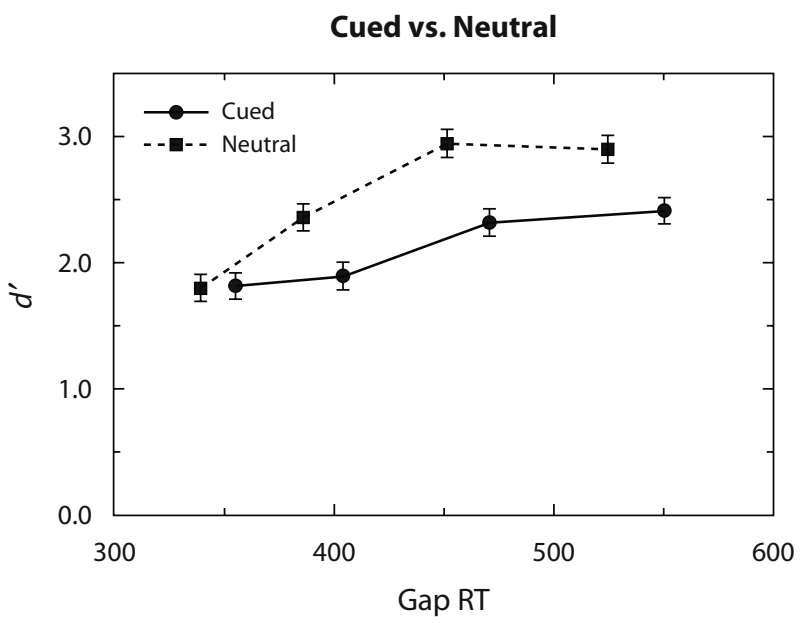

Figure 2. Mean $d^{\prime}$ values for cued versus neutral trials, in Experiment 1, as a function of the gap condition RT. Error bars only represent the main effect in accuracy and are $95 \%$ confidence intervals (Loftus \& Masson, 1994).

moved from the analysis. These proportions did not significantly vary with cuing.

Mean correct RTs to the offset of the first disk were submitted to a repeated measures ANOVA. This analysis included the within-participants factors of cuing (spatially cued trials and neutral cue trials), gap condition (gap and no gap), and STI (191, 263, 335, and $407 \mathrm{msec}$ ). Apart from the main effect of STI, the main effect of cuing was significant $\left[F(1,11)=20.25, M S_{\mathrm{e}}=309, p<.001\right]$. RTs were faster for neutral cue trials than for spatially cued trials. Gap condition was also significant. RT was faster in the gap condition than in the no-gap condition $[F(1,11)=$ $\left.9.75, M S_{\mathrm{e}}=1,526, p=.010\right]$. The interaction between gap and cuing was also significant $\left[F(1,11)=10.53, M S_{\mathrm{e}}=\right.$ $354, p=.008]$, revealing that the cuing effect was observed only in the gap condition. RT never interacted with STI.

Mean accuracy data, as $d^{\prime}$ values, ${ }^{2}$ were submitted to a repeated measures ANOVA, with the factors of cuing and STI. This analysis revealed that both of the main effects were significant. As expected, the STI effect $[F(1,11)=$ $\left.8.33, M S_{\mathrm{e}}=.49, p<.001\right]$ showed an increase in perceptual sensitivity as the STI became longer. The main effect of cuing $\left[F(1,11)=31.96, M S_{\mathrm{e}}=.11, p<.001\right]$ revealed higher perceptual sensitivity to neutral cue trials $(M=2.50)$ versus spatially cued trials $(M=2.11)$. The interaction between STI and cuing was also significant $\left[F(1,11)=2.99, M S_{\mathrm{e}}=.16, p=.045\right]$ and showed that the cuing effect was not present at the short STI (see Figure 2). Criterion ${ }^{3}$ was also examined, but there were no significant effects (see Table 2).

In summary, the present experiment replicated Yeshurun and Levy's (2003) finding. Even when RT is controlled and the decision to respond is made within comparable time windows, perceptual sensitivity to detect a temporal gap is impaired on spatially cued trials as compared with neutral trials. However, contrary to Yeshurun and Levy's findings, we found no criterion shifts for responding on spatially cued and neutral trials.

\section{EXPERIMENT 2 Cued Versus Uncued Trials}

As highlighted in the introduction, the results of Yeshurun and Levy (2003) are difficult to interpret, because the neutral cue and the spatial cue were physically very different. The use of this specific neutral cue likely produced

Table 2

Mean Reaction Times (RTs, in Milliseconds), and Accuracy for the Gap and No-Gap Conditions, Mean $d^{\prime}$, and Response Criterion (c), As a Function of Cuing and STI, in Experiments 1 (Cued vs. Neutral) and 2 (Cued vs. Uncued)

\begin{tabular}{|c|c|c|c|c|c|c|c|c|c|}
\hline & & \multicolumn{8}{|c|}{ Stimulus-Time Interval } \\
\hline & & \multicolumn{2}{|c|}{120} & \multicolumn{2}{|c|}{192} & \multicolumn{2}{|c|}{264} & \multicolumn{2}{|c|}{336} \\
\hline & & RT & Acc. & RT & Acc. & RT & Acc. & RT & Acc. \\
\hline \multicolumn{10}{|c|}{ Experiment 1} \\
\hline Gap & $\begin{array}{l}\text { Cued } \\
\text { Neutral }\end{array}$ & $\begin{array}{l}355 \\
340\end{array}$ & $\begin{array}{l}.80 \\
.80\end{array}$ & $\begin{array}{l}404 \\
386\end{array}$ & $\begin{array}{l}.75 \\
.87\end{array}$ & $\begin{array}{l}472 \\
451\end{array}$ & $\begin{array}{l}.79 \\
.88\end{array}$ & $\begin{array}{l}551 \\
525\end{array}$ & $\begin{array}{l}.80 \\
.87\end{array}$ \\
\hline No gap & $\begin{array}{l}\text { Cued } \\
\text { Neutral }\end{array}$ & $\begin{array}{l}370 \\
367\end{array}$ & $\begin{array}{l}.80 \\
.79\end{array}$ & $\begin{array}{l}418 \\
420\end{array}$ & $\begin{array}{l}.86 \\
.85\end{array}$ & $\begin{array}{l}475 \\
475\end{array}$ & $\begin{array}{l}.89 \\
.93\end{array}$ & $\begin{array}{l}553 \\
544\end{array}$ & $\begin{array}{l}.86 \\
.92\end{array}$ \\
\hline Perceptual sensitivity $\left(d^{\prime}\right)$ & $\begin{array}{l}\text { Cued } \\
\text { Neutral }\end{array}$ & \multicolumn{2}{|c|}{$\begin{array}{l}1.82 \\
1.80\end{array}$} & \multicolumn{2}{|c|}{1.89} & \multicolumn{2}{|c|}{2.32} & \multicolumn{2}{|c|}{2.42} \\
\hline Response criterion (c) & $\begin{array}{l}\text { Cued } \\
\text { Neutral }\end{array}$ & \multicolumn{2}{|c|}{$\begin{array}{l}-0.01 \\
-0.05\end{array}$} & \multicolumn{2}{|c|}{$\begin{array}{r}2.36 \\
0.20 \\
-0.06\end{array}$} & & & & \\
\hline \multicolumn{10}{|c|}{ Experiment 2} \\
\hline Gap & $\begin{array}{l}\text { Cued } \\
\text { Uncued }\end{array}$ & $\begin{array}{l}377 \\
353\end{array}$ & $\begin{array}{l}.73 \\
.66\end{array}$ & $\begin{array}{l}392 \\
397\end{array}$ & $\begin{array}{l}.76 \\
.71\end{array}$ & $\begin{array}{l}452 \\
455\end{array}$ & $\begin{array}{l}.82 \\
.77\end{array}$ & $\begin{array}{l}519 \\
516\end{array}$ & $\begin{array}{l}.81 \\
.83\end{array}$ \\
\hline No gap & $\begin{array}{l}\text { Cued } \\
\text { Uncued }\end{array}$ & $\begin{array}{l}349 \\
350\end{array}$ & $\begin{array}{l}.76 \\
.76\end{array}$ & $\begin{array}{l}408 \\
406\end{array}$ & $\begin{array}{l}.84 \\
.82\end{array}$ & $\begin{array}{l}460 \\
465\end{array}$ & $\begin{array}{l}.90 \\
.85\end{array}$ & $\begin{array}{l}542 \\
531\end{array}$ & $\begin{array}{l}.91 \\
.87\end{array}$ \\
\hline Perceptual sensitivity $\left(d^{\prime}\right)$ & $\begin{array}{l}\text { Cued } \\
\text { Uncued }\end{array}$ & \multicolumn{2}{|c|}{$\begin{array}{l}1.60 \\
1.33\end{array}$} & \multicolumn{2}{|c|}{$\begin{array}{l}1.95 \\
1.63\end{array}$} & \multicolumn{2}{|c|}{$\begin{array}{l}2.51 \\
1.98\end{array}$} & \multicolumn{2}{|c|}{$\begin{array}{l}2.59 \\
2.40\end{array}$} \\
\hline Response criterion (c) & $\begin{array}{l}\text { Cued } \\
\text { Uncued }\end{array}$ & \multicolumn{2}{|c|}{$\begin{array}{l}0.02 \\
0.02\end{array}$} & \multicolumn{2}{|c|}{$\begin{array}{l}0.18 \\
0.19\end{array}$} & \multicolumn{2}{|c|}{$\begin{array}{l}0.17 \\
0.18\end{array}$} & \multicolumn{2}{|c|}{$\begin{array}{l}0.23 \\
0.16\end{array}$} \\
\hline
\end{tabular}


different preparatory states, and probably larger alerting effects, than did the spatial cue. In order to rule out this possibility, performance for cued versus uncued trials was compared in Experiment 2. In this case, the same cue was used in both conditions. More importantly, the participant could not know in advance whether the trial was cued or uncued until the target appeared, making it possible to equate all the cognitive processes involved in the processing of the cue until the moment of target appearance. In the present experiment, the cue was not predictive (i.e., cued and uncued trials were equally likely). As in Experiment 1 , speed stress was controlled by a signal tone that indicated when to respond.

\section{Method}

Participants. A fresh sample of 16 naive participants (3 males and 13 females, mean age of 21 years) from Dalhousie University took part in the experiment for course credits.

Apparatus, Stimuli, and Procedure. Everything was the same as in Experiment 1 except that the cue was always a green horizontal line subtending $1.5^{\circ} \times 0.4^{\circ}$ of visual angle, and situated $0.6^{\circ}$ above the location where targets could be presented. The cue was presented randomly at the left or right location, and the target was also presented randomly at either the same location as the cue (cued trials) or the opposite location (uncued trials).

\section{Results}

Misses ( $8.7 \%$ of trials), late responses (responses $482 \mathrm{msec}$ after the response was required; $0.57 \%$ of the trials), and early responses ( $8.1 \%$ of the trials) were removed from the analysis. These proportions did not vary significantly with cuing.

Mean correct RTs to the offset of the first disk were submitted to a repeated measures ANOVA. This analysis included the factors of cuing (cued and uncued trials), gap condition (gap and no gap), and STI (191, 263, 335 , and $407 \mathrm{msec}$ ), all manipulated within participants. Apart from the main effect of STI, the main effect of gap condition was significant $\left[F(1,15)=5.62, M S_{\mathrm{e}}=1,390\right.$, $p=.032]$. RT was faster in the gap condition than in the no-gap condition. The interaction between STI and cuing was significant $\left[F(1,15)=3.17, M S_{\mathrm{e}}=205, p=.034\right]$, revealing faster RTs for cued than for uncued trials, but only at the shorter STI.

Mean $d^{\prime}$ values were submitted to an ANOVA with the factors of cuing and STI. This analysis revealed a significant main effect of STI $\left[F(3,45)=10.85, M S_{\mathrm{e}}=\right.$ $.622, p<.001]$, indicating that participants' perceptual sensitivity improved as STI increased. The main effect of cuing was also significant $\left[F(1,15)=42.32, M S_{\mathrm{e}}=\right.$ $.079, p<.001$, revealing that perceptual sensitivity was increased for cued trials as compared with uncued trials (see Figure 3). The interaction between STI and cuing was not significant $(F<1)$. (See Table 1.) Criterion was also analyzed, but none of the main effects or interactions approached significance.

In sum, the results of this experiment showed that when the speed of response was controlled and decisions were made within comparable time windows, perceptual sensitivity was actually improved for cued trials as compared with uncued trials. Moreover, no evidence of an SAT was found in this experiment, RT being even faster in cued than in uncued trials at every STI. Additionally, as in our Experiment 1, no effects on criterion were observed when participants responded to cued versus uncued targets.

\section{DISCUSSION}

A recent line of research has suggested that attention is not beneficial for all tasks: Although it enhances spatial resolution (Yeshurun \& Carrasco, 1998), it might impair performance in temporal-resolution tasks (Rolke et al., 2008; Yeshurun, 2004; Yeshurun \& Levy, 2003). In the first studies (Yeshurun \& Levy, 2003), spatial cues were compared with neutral cues that were much bigger and more salient. Subsequent studies (Hein et al., 2006; Rolke et al., 2008) did correct this by comparing targets preceded by a same spatial cue that could appear at the same location (cued trials) or at the opposite location (uncued trials) as that of the target. However, when cued and uncued trials have been compared, SATs have always been observed, which makes drawing strong conclusions difficult, if not impossible.

In the experiments reported in this article, we controlled the SAT effects using a deadline method for responding. We constrained RT in different blocks of trials, so that decisions would be made within comparable time windows, and thus the changes in perceptual sensitivity would not likely be affected by unexpected SATs. In Experiment 1, we replicated Yeshurun and Levy's (2003) finding, even when response speed was controlled. We found that when responses had to be made within comparable time windows, perceptual sensitivity was still impaired for spatially cued trials as compared with neutral trials. In Experiment 2, we compared perceptual sensitivity on cued and uncued trials, while again using the deadline method to constrain RTs. This time, perceptual sensitivity was improved for cued versus uncued trials, revealing that spatial attention enhanced temporal resolution.

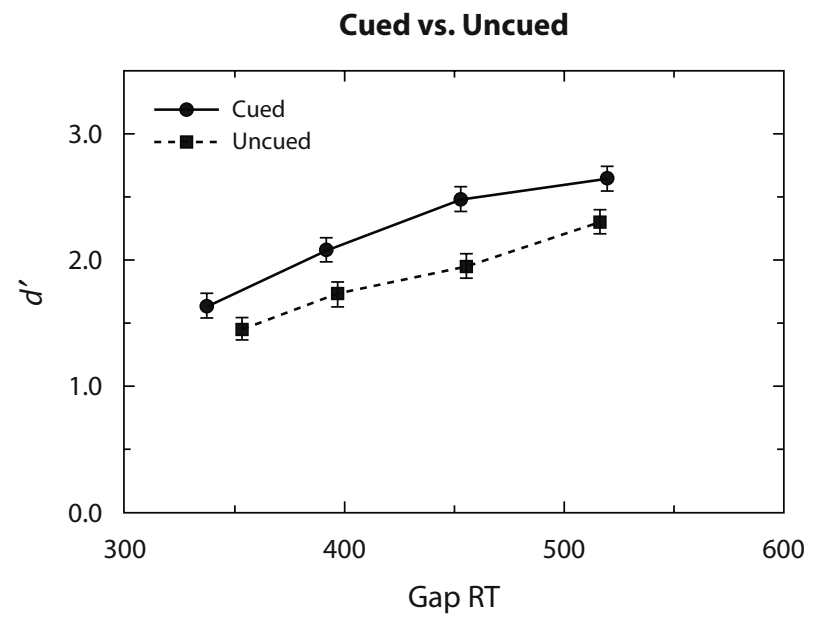

Figure 3. Mean $d^{\prime}$ values for cued versus uncued trials, in Experiment 2, as a function of the gap condition RT. Error bars represent only the main effect in accuracy and are $95 \%$ confidence intervals. 
Rolke et al. (2008, Experiment 3) also tried to control for the SAT observed in their experiments. They asked participants to withhold their responses until an imperative sound was presented after $1 \mathrm{sec}$. Under this condition, no cuing effect on RT was found, but, still, perceptual sensitivity was poorer for cued than for uncued trials. Why do our results differ from Rolke et al.'s (2008), when they tried to control for the SAT effect? The major difference between Rolke et al.'s (2008) manipulation and ours is that we constrained RT to a maximum time to respond of $336 \mathrm{msec}$ after the target's offset, whereas they delayed the response until well after the decision was likely made (1 sec). In Rolke et al.'s (2008) manipulation, participants could make their decision to respond in a broad temporal window, and it is possible that decisions were made well before the 1-sec deadline. There is no reason to believe that delaying the response until well beyond typical RTs changed the time at which the decision was made in Rolke et al.'s (2008) study. In the present experiments, decisions were made in more restricted time windows, and this gave rise to opposite $d^{\prime}$ results (enhanced perceptual sensitivity in cued trials). Therefore, it seems plausible to conclude that, when the actual time of decision is constrained and an SAT cannot occur between conditions, accuracy is better for cued than for uncued targets. This conclusion coincides with a further analysis of SAT data from Rolke et al.'s (2008) Experiment 2, which shows that the actual RT effect size is larger than the accuracy one, suggesting that they should have gone with the RT conclusion (cuing-improved performance) rather than the accuracy one (cuing-hindered performance).

Another difference between Rolke et al.'s (2008) experiment and ours is that whereas they used an informative peripheral cue that attracted both endogenous and exogenous attention, we used a noninformative peripheral cue that oriented attention exogenously. It does not seem very plausible that endogenous attention was responsible for the impaired performance in cued versus uncued trials, because when Hein et al. (2006, Experiment 2) used a central informative cue and compared performance in a TOJ task, they found that endogenous attention to the location indicated by the arrow enhanced performance. These results are also consistent with a recent article exploring the effect of attention in a temporal-resolution and attentional-blink task (Rolke, Bausenhart, \& Ulrich, 2007). The attentional blink refers to an impairment in consciously perceiving a stimulus when attentional resources are busy (normally for having reported another stimulus shortly after). Rolke et al. (2007) used a gap detection task that was preceded by a letter-discrimination task or a control condition in which no task had to be performed before the gap detection. If attention impairs temporal resolution, gap detection should be enhanced when participants' attentional resources are busy with the letter-discrimination task. However, the results revealed a performance decrement when attention was temporally unavailable during the attentional blink, suggesting that focused attention during the task improved performance.

If the present conclusions are correct, they would appear to reject Yeshurun and Levy's (2003) theory that orienting spatial attention involves activating a slower parvocellular system (and inhibiting the magnocellular one), which diminishes temporal acuity. However, there is some evidence that such a theory of the underlying mechanisms may play a role within larger attentional networks that serve expected functions of improving performance. On the basis of the present results, we argue that, due to its higher salience, Yeshurun and Levy's neutral cue produced larger alerting effects than did the spatial cue, and that the resulting increased response preparation overcame the spatial cuing effect. Yeshurun and Levy also found that their cuing manipulation enhanced performance in a spatial task. Therefore, the present finding appears specific to temporal targets. One explanation for these discrepancies is that spatial cuing facilitates spatial tasks better than it does temporal tasks. Conversely, alerting and temporal-resolution tasks may be matched, such that being more alert also increases temporal-task performance more than it does spatial-task performance. Within such a framework, the activation of slower parvocellular neurons is one of the ways in which spatial attention may be less well adapted to optimizing temporal discriminations. Similarly, there may be temporal attention properties that are not well adapted to spatial tasks. For example, a general increase in sensitivity due to increased alertness to all signals may not enhance spatial acuity, because both noise and signal increase.

To summarize, in the present experiments we have demonstrated that, when response decisions are made within comparable time windows, exogenous attention does in fact improve temporal resolution. This result provides an argument against Yeshurun and Levy's (2003) assertion that spatial attention impoverishes temporal acuity. It still needs to be explained why SATs are observed so often in temporal-resolution tasks and to be determined which mechanisms lead the system to respond fast, but less accurately, to exogenously attended locations. Moreover, it would be interesting to understand the effects of alerting on temporal tasks and how they differ from those for spatial tasks. This would be necessary in order to explain Yeshurun and Levy's finding that alerting was more powerful than orienting within their temporal target experiments but that this pattern was reversed in the spatial task.

\section{AUTHOR NOTE}

The authors thank Raymond M. Klein for his helpful comments on this project. This research was supported by the National Science and Engineering Research Council of Canada (NSERCC grant to Raymond M. Klein), the Spanish Ministerio de Educación y Ciencia (Predoctoral Grant AP-2004-1509 to A.B.C.), and the Sobey Foundation (postdoctoral grant to J.C.). Address correspondence to A. B. Chica, Departamento de Psicología Experimental y Fisiología del Comportamiento, Campus de Cartuja, S/N. C.P. 18071, Granada, Spain (e-mail: anachica@ugr.es).

Note-Accepted by the previous editorial team, when Thomas H. Carr was Editor.

\section{REFERENCES}

BALDASSI, S., \& BURR, D. C. (2000). Feature-based integration of orientation signals in visual search. Vision Research, 40, 1293-1300.

Cameron, E. L., Tai, J. C., \& Carrasco, M. (2002). Covert attention 
affects the psychometric function of contrast sensitivity. Vision Research, 42, 949-967.

Chica, A. B., Lupiáñez, J., \& Bartolomeo, P. (2006). Dissociating inhibition of return from the endogenous orienting of spatial attention: Evidence from detection and discrimination tasks. Cognitive Neuropsychology, 23, 1015-1034.

Hein, E., Rolke, B., \& Ulrich, R. (2006). Visual attention and temporal discrimination: Differential effects of automatic and voluntary cueing. Visual Cognition, 13, 29-50.

IVANOFF, J., \& KleIN, R. M. (2006). Inhibition of return: Sensitivity and criterion as a function of response time. Journal of Experimental Psychology: Human Perception \& Performance, 32, 908-919.

Jonides, J., \& MACK, R. (1984). On the cost and benefit of cost and benefit. Psychological Bulletin, 96, 29-44.

KLEIN, R. M. (2004). On the control of visual orienting. In M. I. Posner (Ed.), Cognitive neuroscience of attention (pp. 29-44). New York: Guilford.

Levine, M. W. (2000). Fundamentals of sensation and perception. New York: University Press.

Loftus, G. R., \& Masson, M. E. J. (1994). Using confidence intervals in within-subject designs. Psychonomic Bulletin \& Review, 1, 476-490.

McCormick, P. A., \& Francis, L. (2005). Speed-accuracy tradeoff operator characteristics of endogenous and exogenous covert orienting of attention. Scientific World Journal, 5, 128-146.

Merigan, W. H., \& Maunsell, J. H. R. (1993). How parallel are the primate visual pathways? Annual Review of Neuroscience, 16, 369-402.

Posner, M. I., \& Cohen, Y. (1984). Components of visual orienting. In H. Bouma \& D. G. Bouwhuis (Eds.), Attention and performance X: Control of language processes (pp. 531-556). Hillsdale, NJ: Erlbaum
Rolke, B., BAUSENhart, K. M., \& Ulrich, R. (2007). Impaired temporal discrimination within the attentional blink. Perception \& Psychophysics, 69, 1295-1304.

Rolke, B., Dinkelbach, A., Hein, E., \& Ulrich, R. (2008). Does attention impair temporal discrimination? Examining non-attentional accounts. Psychological Research, 72, 49-60.

Schneider, W., Eschman, A., \& Zuccolotto, A. (2002). E-Prime user's guide. Pittsburgh: Psychology Software Tools.

YESHURUN, Y. (2004). Isoluminant stimuli and red background attenuate the effects of transient spatial attention on temporal resolution. Vision Research, 44, 1375-1387.

Yeshurun, Y., \& CARRAsco, M. (1998). Attention improves or impairs visual performance by enhancing spatial resolution. Nature, 396, $72-75$.

Yeshurun, Y., \& Levy, L. (2003). Transient spatial attention degrades temporal resolution. Psychological Science, 14, 225-231.

\section{NOTES}

1. When a peripheral cue predicts that the target would be presented at this location, the cue captures attention exogenously, but endogenous attention is also maintained at this location. Therefore, the behavioral effect produced by the cue could be due to exogenous attention, to endogenous attention, or to a combination of both.

2. $d^{\prime}$ was calculated as the quantile under the normal distribution of the hit proportion minus the proportion of false alarms.

3. Criterion (c) was calculated as -0.5 times the sum of the hit and false-alarm quantiles.

(Manuscript received April 18, 2007; revision accepted for publication September 29, 2008.) 